\title{
Awareness, Health Seeking Behaviors and Preventive Measures towards COVID-19 among Najran University Students
}

\author{
Mohammed Alshahrani ${ }^{1}$, Abdullah Aedh ${ }^{1}$, Nahid Elfaki ${ }^{1}$, and Hanan Alwadei ${ }^{1}$ \\ ${ }^{1}$ Affiliation not available
}

August 3, 2020

\begin{abstract}
Background: New corona virus (COVID-19), as an international health threat poses a challenge to physical and psychological resilience globally. The aim of this survey is to explore the level of awareness, health seeking behaviors and preventive measures towards COVID19 among Najran university students. Methodology: By adopting a convenient sampling technique, a crosssectional study was carried out at Najran university. A self-reporting electronic questionnaire had been utilized for collecting data. A total of 684 students were voluntary completed the questionnaire. Results: The mean age of the participants was $20.2 \pm 14.1$, The most cited source for obtaining information about COVID-19 was the social media (51\%). Females showed higher level of knowledge and awareness about the symptoms of the disease than males ( $74.3 \%$ vs $69.9 \%)$ respectively, although the difference was not significant with (P-value $>0.05$ ). In regard to compliance with preventive measures, medical students were significantly aware and complying with various preventives measures towards COVID-19 (P-value $<0.05$ ). Moreover, females seem to be very keen in seeking medical advices when needed significantly more than males $(\mathrm{P}$-value $<0.05)$. Almost more than $66 \%$ of the respondents know the recommended precautions in terms of wearing masks, not to touch outdoors surfaces directly and avoiding crowded places. 556(81.3\%) of the participants believe that they should wear face masks outdoors. $6 \%$ of the participants prefer to take some herbs daily in different forms to avoid getting infected with COVID-19. Females had an overall higher mean of tension level towards getting infected than males (mean \pm SD was $5.61 \pm 1.65$ vs $4.55 \pm 1.63$ ) respectively. Conclusion: It was concluded that our students have high level of knowledge and awareness about COVID-19, beside positive attitudes preventive measures and acceptable health seeking behaviors. It is highly recommended to assess the entire Najran community level of awareness so as to design educational programs when needed.
\end{abstract}

\section{Introduction}

Starting from December 2019, the number of Novel Corona-virus (nCOV-2019) cases are increasing dramatically especially in Middle East countries, although they are declining in some countries worldwide including China which is the original source of this pandemic ${ }^{1,2}$. Corona-virus is a highly contagious disease which caused by group of viruses with different genetic compositions that invading the respiratory system and therefore, it causes numerous respiratory health problems ranging from mild common cold symptoms to fatal pneumonia ${ }^{3}$.

It had been reported that people who are at greater risk for developing severe symptoms are elderly people besides those with chronic health disorders such as hypertension, diabetes, cardio-vascular diseases, chronic respiratory disorders and cancers. Although, for children appears to be relatively rare and mild ${ }^{4,5,6}$.

However, the underlying pathological mechanisms that let some infected people to get seriously sick while others get mild symptoms, still unknown ${ }^{7}$. This disease of unknown etiology and source let WHO and most countries to adopt strict international precautions to stop spreading of the disease ${ }^{8,9}$. These strict precautions beside social media speculations and closing off all places including academic institutions as 
well as increasing deaths anywhere put people in psychological distress that generates negative emotions for individuals, families and entire communities ${ }^{10}$.

Moreover, to date, there have been no definite treatment or vaccines for this disease ${ }^{11,12}$. Therefore, it is very important for people to be aware about this pandemic in terms of its etiology, signs and symptoms, mode of transmission and obviously how to prevent spreading of the disease beside how and when to seek and ask for medical advices and assistance.

Saudi Arabia has had a vast majority of infected cases with COVID-19 among Middle East countries. The cases ranged from asymptomatic contacts, being suspected, positively diagnosed up to manifestations of severely pulmonary damaged cases ${ }^{13,14}$. This outbreaks can put significant psychological stress on people which may lead to unfavorable effects on the overall physical, psychological as well as emotional stability ${ }^{15}$.

Numerous studies documented that fear from death and pervasive feelings of anxiety, loneliness, sadness, irritability and other serious concerns may arise among healthy people during pandemics ${ }^{16,17}$. Despite the importance of physical as well as psychological problems during this pandemic occurrence, so much contradicted information is available about COVID-19 in various social media and internet sites. Therefore, public awareness about the nature of this virus and how to prevent it may decrease such irritability and other unfavorable problems. Moreover, good, right and reliable information would be useful in improving preventive strategies beside aiding in designing proper health education programs for controlling the disease.

Accordingly, it is necessary to conduct such surveys for assessing the awareness level among populations.

The aim of this study was to explore the awareness, health seeking behaviors and preventive measures towards COVID-19 among Najran University students during this outbreak.

\section{Materials and Methodology}

By adopting a convenient sampling technique, an observational and cross-sectional study was carried out at Najran University during the period from March - to- June, 2020. 684 students were voluntary participated in the current study.

For collecting data, a self-reporting electronic questionnaire was utilized. The questionnaire was reviewed for validity by experts at the faculty of nursing which shows an acceptable internal consistency (Cronbach's alpha, $r=0.895$ ). Additionally, the questionnaire was pilot tested on 20 subjects from the target population, who were excluded in this study. Beside that, the questionnaire explains the aim of the study along with assuring the participants' confidentiality.

\section{Statistical Analysis}

Continuous variables were expressed in term of means, standard deviation (SD). While the categorical variables were calculated as numbers and percentages. Associations between students' characteristics and responses about COVID-19 awareness, health seeking behaviors and preventive measures were assessed by bivariate analysis using $\chi^{2}$ tests and $t$ - test. Comparison of scores between groups was based on analysis of variance chi-square and one-way ANOVA test. $P$-value was set at $<0.05$.

\section{Results}

684 participants were voluntary completed the current survey. Table (1) shows the demographic characteristics of the participants. In terms of gender, female students were 405 that represents $59.2 \%$ of the participants. The mean age of the studied subjects was $20.21 \pm 4.1$, the minimum was 19 years and the maximum was 26 years old. With respect to the respondents' college affiliation, the majority of them are currently enrolled in non-medical colleges $398958.2 \%$ ). In regard to level of education, the vast majority of the surveyed sample $516(75.44 \%)$ are currently studying in bachelor programs.

Medical colleges include medicine, nursing, dentistry, pharmacy and radiology. While non-medical colleges include college of art, computer sciences, community preparatory college, college of Sharia and college of education. 
As displayed in figure (1), the most cited source for getting information and news about COVID-19 was social media (51\%), followed by news from TVs' channels (38\%), while the least cited source was the families $(29 \%)$.

\section{Awareness about COVID-19 symptoms and rout of transmission}

In general the responses to the awareness questions regarding symptoms and route of transmission of COVID19 were displayed in table (2). It shows that the majority of the respondents 496 (72.51\%) were correctly identified its typical symptoms. While in regard to routes of transmission, most of the participants 524 $(76.6 \%)$ show awareness about the disease's route of transmission correctly, although the differences between males and females regarding the awareness were not statistically significant $(P$-value $>0.05)$.

Almost all respondents had heard that the numbers of infected individuals are increasing worldwide. The majority of the studied subjects $(75.1 \%)$ were satisfied with the quality and quantity of information that available and accessible for them at Saudi ministry of health official web site. Regarding knowledge about route of transmission of COVID-19, the most cited route of transmission by participants was through sneezing or coughing and personal contact (46\%), followed by through contaminated objects outdoors (31\%), and airborne transmission route was cited by $(18 \%)$ of the participants, while only $5 \%$ don't know.

The results of the one-way ANOVA as shown in table (3) reveals a significant difference between the means of students' health seeking behaviors according to their levels of information about COVID-19 $\left[\mathrm{F}_{(3-277)}=4.286\right.$, $P$-value $<0.05]$ based on their own perceptions respectively.

Table (4) reflects the overall significant predictors of awareness, preventive measures and health seeking behaviors towards COVID-19. It shows that medical students were significantly have higher level of awareness, compliance with preventive measures and of course for health seeking behaviors $(P$-value $<0.05)$. In comparison between males and females in regard to health seeking behaviors, the results surprisingly reveal that females have positive behaviors towards health seeking attitudes than males.

\section{Behaviors towards precaution and preventive measures}

Almost two third of the studied respondents know the recommended general precautions in terms of not to touch outdoors' surfaces and objects with hands directly. $556(81.3 \%)$ of the subjects believe that they should wear face masks when going outside their homes, while $6 \%$ agree that they should take some herbs daily to avoid getting infected with the virus. Female students had an overall higher mean of tension level than males (Mean $\pm \mathrm{SD}$ was $5.61 \pm 1.65$ vs. $4.56 \pm 1.63$ ) respectively.

\section{Discussion}

COVID-19 pandemic in Saudi Arabia as other countries around the globe is considered one of the most challenging threats to national public health. Since there is no vaccine or treatment for COVID-19, awareness about it is crucial for preventing the spread of this pandemic. Therefore, the main goal of the current study was to assess the level of awareness, health seeking behaviors and preventive measures towards COVID-19. The findings reveal that, although some variability was noted in knowledge in regard to COVID-19 causes, symptoms and route of transmission. $72.51 \%$ of the participants in the current study have good knowledge and they correctly identified the causes, symptoms and route of transmission of the disease.

The high level of awareness among our university students could be due to the effectiveness of different awareness campaigns that were conducted by Saudi Ministry of Health around the country beside the abundant information that available in social media. This finding was in accordance with what had been reported by Pranav et al. who concluded that $71.2 \%$ of their studied students in Mumbai (India) were reporting correct answers regarding the awareness about COVID- $19^{18}$. Although, it is a bit less than what had been reported by Alzoubi et al who stated that the level of awareness about symptoms of COVID-19 among their studied sample in Jordan which was more than $90 \%{ }^{19}$.

In contrast our obtained result regarding awareness is higher than what had been concluded by by Rhea et al in India (48\%) and also higher than what had been reported by Chesser et al in USA at Wichita State 
University which was only $18 \%$ of their sample identified the symptoms correctly ${ }^{20,21}$.

The possible explanation of the differences between these results could because the data collection processes performed by different measurement instruments as well as the different sample sizes and different populations with different cultures.

In regard to source of information for the students about COVID-19 issues, the majority of the participants in the current study $51 \%$ cited that social media was their main source. Interestingly, this obtained result support the evidences published in numerous of studies, indicating that the most cited source of getting information regarding COVID-19 was the social media ${ }^{22,23,18}$. This could be due to the fact that this age generations are called techno-generation in most countries.

In terms of health seeking behaviors, our study concluded that 556(81.3\%) of our studied participants believe that they should wear face mask when leaving their homes. The highest percentage of positive responses were significantly noticed among medical students. The findings of the current study in this specific matter are similar to those from other studies that conducted in India, Jordan and China ${ }^{18,19,24}$. Additionally, college affiliation was significantly has an impact on the total knowledge and behavior scores among the students which was high among those at medical colleges.

\section{Conclusion and Recommendation}

In conclusion, COVID-19 outbreak can be avoided by adopting certain precautions that include frequent hand washing with soap and water for at 40 minutes, avoiding unnecessary going outside homes, beside wearing masks in public places. The current study shows that the undergraduate students in different colleges at Najran University have adequate knowledge and awareness about the different aspects of COVID-19 in terms of recognizing its symptoms, beside the recommended preventive precautions that should be taken seriously. Although, the students showed adequate knowledge with an overall percentage of $72.51 \%$ correct answers, but more emphasis should be put on updating their knowledge regarding the upcoming events about COVID-19 periodically for controlling the spreading of the disease.

Moreover, raising the level of awareness and knowledge about this pandemic will help not only the university students, but also can encourage the suspected and those at risk individuals to seek medical help as early as possible and thus to be treated properly and timely.

\section{Declaration}

The authors declared no potential conflicts of interest with respect to the research, authorship and/ or publication for this article.

\section{References}

1. Wu F, Zhao Su, Yu B et al. A new coronavirus associated with human respiratory disease in China. Nature J. March, 2020; 579(7798): 265- 269.

2. Fauci AS, Clifford Lane A and Redfield RR. COVID-19- Navigating the uncharted. New England Journal of Medicine. March, 2020. 382(13): 1268-1269.

3. Suman R, Javaid M, Haleem A, Vaishy R, Bahl S and Nandan D. Sustainability of Coronavirus of Different Surface. J Clin Exp Hepatol. May, 2020. Retrieved May, 2020 from the following web site: https://www.ncbi.nlm.nih.gov/pmc/articles/PMC7201236/

4. Chen N, Zhou M, Dong X, Qu J, Gong F, Han Y et al. Epidemiological and clinical characteristics of 99 cases of 2019 Novel Coronavirus pneumonia in Wuhan, China: A descriptive study. LANCET. February, 2020. 395(10223): $507-513$.

5. Fang L, Karakiulakis G, Roth M. Are patients with hypertension and diabetes mellitus at increased risk for COVID-19 infection?. The Lancet Respiratory Medicine. March, 2020. 395(10224): 35-36.

6. Ayesha Mirza, Mary L Windle, John Anello, David J Cennimo: Coronavirus Disease 2019 (COVID-19) in Children. Medscape. June, 2020. Retrieved May, 2020 from the following web site: https://emedicine.medscape.com/article/2500132-overview. 
7. Strindhall J, Nilsson BO, Lofgren S et al. No Immune Risk Profile among Individuals who reach 100 Years of Age: Findings from Swedish NONA immune longitudinal study. Exp Gerontol. 2007; 42(8): 753-761.

8. World Health Organization (n.d). Coronavirus disease (COVID-19) outbreak, Retrieved June, 2020 from the following web site: https://www.who.int/emergencies/diseases/novelcoronavirus-2019.

9. WHO Coronavirus Disease (COVID-19) Dashboard: cited from the following web site: Https://covid19. who.int/?gclid=cj0KCQ.jwuJz.3BRDTARIsAMg-HxW3y-CHJcxqu5D3Vlp5vnb2Ylaqftp08YAKPZlgoJluBxR3oce-R8aArlaEALW.wcB.

10. Cao W, Fang Z, Hou G et al. The psychological impact of the COVID-19 epidemic on college students in China. Psychiatry Res J. May, 2020. 278:112934. Cited June, 2020 from the following web site https://www.ncbi.nlm.nih.gov/pmc/articles/PMC7102633/

11. Huang C, Wang Y, Li X, Ren L, Zhao J, Hu Y, et al. Clinical features of patients infected with 2019 Novel Coronavirus in Wuhan, China. LANCET, 2020; 395(10223): 497-506.

12. Jaume M, Yip MS, Cheung CY,. Et al. Anti-severe acute respiratory syndrome coronavirus spike antibodies trigger infection of human immune cells via a PH-and cysteine protease-independent FcyR pathway. J Virol. 2011; 85(20): 10582-10597.

13. Saudi Ministry of Health (MOH) website: https://www.moh.gov.sa/en/HealthAwareness/EducationalContent/PublicH

14. World Health Organization. (nd.). Coronavirus Disease Situation Reports. Retrieved March, 2020 from the following website: https://www.who.int/emergencies/diseases/novel-coronavirus-2019/situationreports

15. Shigemura J, Ursano RJ, Morganstein JC, Kurosawa M, Benedek DM. Public responses to the novel 2019 coronavirus (2019-nCoV) in Japan. Mental health consequences and target populations. Psychiatry Clin Neurosci. Feb. 2020; 74(4): 281-282.

16. Garfin DR, Silver RC, and Holman EA. The novel coronavirus (COVID-19) outbreak: Amplification of public health consequences by media exposure. Health Psychology: Official Journal of thr Division of Health Psychology, American Psychological Association. 2020; 39(5):355-357.

17. Mental health and psychological considerations during the COVID-19 outbreak. Retrieved May, 2020 from the following website: https://www.who.int/docs/default-source/cprpnaviruse/mental-healthconsiderations.pdf

18. Pranav Modi PD, Nair G, Uppe A et al. COVID-19 Awareness Among Healthcare Students and Professionals in Mumbai Metropolitan Region: A Questionnaire-Based Survey. Cureus. April, 2020; 12(4): $1-18$.

19. Hamed Alzoubi, Nedal Alnawaiseh, Asma'a Al-Mnayyis, Mohammad Abu-Lubada, Amin Algel and Hani Al-Shagahin. COVID-19 Knowledge, Attitude and Practice among Medical and Non-Medical University Students in Jordan. J Pure Appl. Microbiol. 2020; 14(1): 17-24.

20. Rhea Vivek Kashid, Asawari Awadhut Shidhore, Mohammad Mukhit Kazi, Sameer Patil. Awareness of COVID-19 amongst undergraduate dental students in India- A questionnaire based cross-sectional study; May, 2020. Retrieved June, 2020 from the following website: https://www.researchsquare.com/article/rs-27183/v1

21. Chesser A, Drassen Ham A, Keene Woods N. Assessment of COVID-19 Knowledge Among University Students: Implications for Future Risk Communication Strategies. Health Educ. Behav. May, 2020; 47(1): $1-4$.

22. Labban L, Thallaj N, Labban A. Assessing the level of Awareness and Knowledge of COVID-19 Pandemic among Syrians. Arch Med. March, 2020; 12(2): 1-8.

23. Muhammad Yousuf A,li and Rubina Bhatti: COVID-19 (Coronavirus) Pandemic: Information Sources Channels for the Public Health Awareness. Asia Pacific Journal of Public Health. May, 2020; 1-2. Retrieved June, 2020 from the following website: https://journals.sagepub.com/dol/full/10.1177/1010539520927261.

24. Yaling Peng, Chenchen Peiz, Yan Zheng, Juan Wang, Kui Zhaohui Zheng, Ping Zhu: Knowledge, Attitude and Practice Associated with COVID-19 among University Students: a Cross-Sectional Survey in China. BMC-Research square J. April, 2020 Retrieved June, 2020 from the following website: 
https://www.researchsquare.com/article/rs-21185/v1.

\section{Hosted file}

Figure.docx available at https://authorea.com/users/348111/articles/473603-awareness-healthseeking-behaviors-and-preventive-measures-towards-covid-19-among-najran-universitystudents

\section{Hosted file}

Iselectlanguage\{english\}tables.docx available at https://authorea.com/users/348111/articles/ 473603-awareness-health-seeking-behaviors-and-preventive-measures-towards-covid-19among-najran-university-students 